\title{
The Underlying Stroke Etiology: A Comparison of Two Classifications in a Rural Setup
}

\author{
Avani R. Patel ${ }^{1}$, Amar R. Patel ${ }^{1}$, Soaham Desai ${ }^{2}$ \\ 1. Internal Medicine, Northern California Kaiser Permanente, Fremont, USA 2. Neurology, Pramukhswami Medical \\ College, Karamsad, IND
}

Corresponding author: Amar R. Patel, a_patel1993@yahoo.com

\section{Abstract \\ Introduction}

This study compares the Trial of Org 10172 in Acute Stroke Treatment (TOAST) and the atherothrombosis, small vessel disease, cardiac pathology, other causes, and dissection (ASCOD) classification performed in a rural hospital setup. Stroke is the second leading cause of death after ischemic heart disease with over 9.5 million new cases of ischemic stroke in 2016. Stroke is a complex disease with numerous contributing factors. India needs a standardized stroke classification system, as without one it becomes difficult to collect data on stroke patients, perform follow-ups, and provide appropriate secondary prevention. A standardized stroke classification system would also help in building a nationwide database in order to note epidemiological trends of ischemic stroke. This would also create greater awareness regarding stroke in rural parts of India where healthcare is difficult to access.

\section{Aims and objectives}

Our aim was to review all admitted stroke patients' data and classify their etiology and mechanism based on the TOAST and ASCOD classification systems. The ASCOD classification has yet to be utilized in the Indian population. The two classifications are then compared in order to gain a better insight into which classification is a better fit for the Indian population. Both are based on the etiology of ischemic stroke but the ASCOD classification differs because it gives suitable secondary prevention measures based on the diseases linked to stroke. ASCOD also gives a proper indication of the patient's present causative factor (similar to TOAST) and other factors that can possibly lead to further recurrences. This is different from TOAST, which denotes only a single cause for stroke and eliminates the possibility of other involved contributing factors.

\section{Materials and methods}

All patients involved in the study were admitted to a rural Indian hospital from January 2014 to July 2016 . All the relevant clinical details of each patient were then retrieved from the hospital's electronic medical record system for the study. We then classified all the patients based on the TOAST and ASCOD classification criteria.

Received 06/17/2019

Review began 06/25/2019

Review ended 07/01/2019

Published 07/17/2019

๑) Copyright 2019

Patel et al. This is an open access article distributed under the terms of the Creative Commons Attribution License CC-BY 3.0., which permits unrestricted use, distribution, and reproduction in any medium, provided the original author and source are credited.

\section{Results}

Using the ASCOD classification, we found that 179 (86\%) patients out of 209 had either atherothrombosis or small vessel disease. The ASCOD classification also showed substantial evidence that the determined stroke mechanism/etiology is interconnected to multiple causal factors in over $50 \%$ of patients. In contrast, the TOAST classification had identified a larger number of ischemic stroke patients as having an etiology of other and undetermined causes as compared to the ASCOD classification.

\section{Conclusion}

The ASCOD classification is better to use in patients and helps decide the secondary prevention appropriately.

Categories: Internal Medicine, Neurology

Keywords: ischemic stroke, rural healthcare, toast classification, ascod classification, atherothrombosis, cardiac pathology, other causes, dissection, small vessel disease, hypertension

\section{Introduction}

The World Health Organization defines stroke as rapidly developing clinical signs of focal (and sometimes global) disturbance of cerebral function lasting more than 24 hours or leading to death with no apparent cause other than that of vascular origin [1]. Strokes can be divided into hemorrhagic stroke and ischemic stroke. In our study, we aim to compare two different etiological classifications of ischemic stroke. Ischemic stroke has been defined as an episode of neurological dysfunction that is caused by a localized cerebral, 
spinal, or retinal infarction [2]. It is associated with risk factors such as hypertension, diabetes mellitus, smoking, dyslipidemia, alcohol consumption, drug abuse, previous stroke, previous transient ischemic attack, migraine history, atrial fibrillation, coronary artery disease, and family history of stroke among first and second-degree relatives [3].

Stroke has been determined to be a major leading cause of disability and the second leading cause of death [4]. In 2016, the Global Burden of Diseases, Injuries, and Risk Factors Study (GBD) established that there were 5.5 million (95\% uncertainty interval [UI]: 5.3-5.7) deaths and loss of 116.4 million (95\% UI: $111.4-$ 121.4) disability-adjusted life-years (DALYs) due to stroke [5]. GBD also reported that the year 2016 had over 9.5 million new cases of ischemic stroke, of which almost $60 \%$ occurred in patients under 70 years of age [6]. Also, there were over 2.7 million deaths attributable to ischemic stroke in the year 2016 [6].

Countries like India are seeing an increasing number of stroke cases and believe that larger academic studies can bring more awareness on a national level. This awareness relates to the criteria by which ischemic stroke is classified. India has a vast population, and many differences exist between different regions of the country in relation to stroke. Different studies use different ways of classification regarding stroke etiology and mechanism. A unified system of assessment and classification of patients of ischemic stroke based on etiology will need to be utilized to compare and contrast stroke cases across the country. Two etiologic classifications that are commonly used are the Trial of Org 10172 in Acute Stroke Treatment (TOAST) and the atherothrombosis, small vessel disease, cardiac pathology, other causes, and dissection (ASCOD) classification [7-8]. The TOAST classification subcategories are large artery atherosclerosis (LAA), small vessel disease (SVO), cardiac embolism (CE), other causes, and undetermined causes [7]. The ASCOD classification subcategories are atherothrombosis (A), small vessel disease (S), cardiac pathology (C), other causes (O), and dissection (D) [8]. The TOAST classification pinpoints a single determinant as the cause of stroke. In contrast, the ASCOD classification lists all possible phenotypes that could potentially cause stroke and grades each subcategory according to the level of evidence available [8]. There is a lack of data regarding risk factors, etiology and the mechanism of stroke in India. Worldwide, studies have demonstrated that not only is stroke a major cause of death in the adult population, but there is still a lack of data regarding its etiology. Our aim for this study was to review ischemic stroke patients and classify their stroke etiology based on the two classification systems mentioned earlier. We utilized two systems in this study in order to gain insight into which system is a better fit for describing stroke etiology across the Indian population.

\section{Materials And Methods}

The study population consisted of ischemic stroke patients admitted to a rural Indian hospital from January 2014 to July 2016. The name of the rural hospital is Shree Krishna Hospital and is located in the western state of Gujarat, India. For the study, 209 patients were selected. The patient's data were collected from the hospital's electronic medical record system. Relevant data included each patient's demographic information, baseline risk factors, presenting complaints, stroke severity, diagnostic evaluations, and secondary prevention treatments. Diagnostic evaluations included brain imaging, computed tomography (CT), magnetic resonance angiography (MRA), electrocardiogram (ECG), and echocardiography (see Figure 1). Secondary prevention consisted of anticoagulant treatment, antiplatelet treatment, statin treatment, and thrombolysis. Each patient's personal information was removed from the data in order to preserve patient confidentiality. Patients were classified according to the TOAST and ASCOD classification systems [7-8]. 


\section{Cureus}

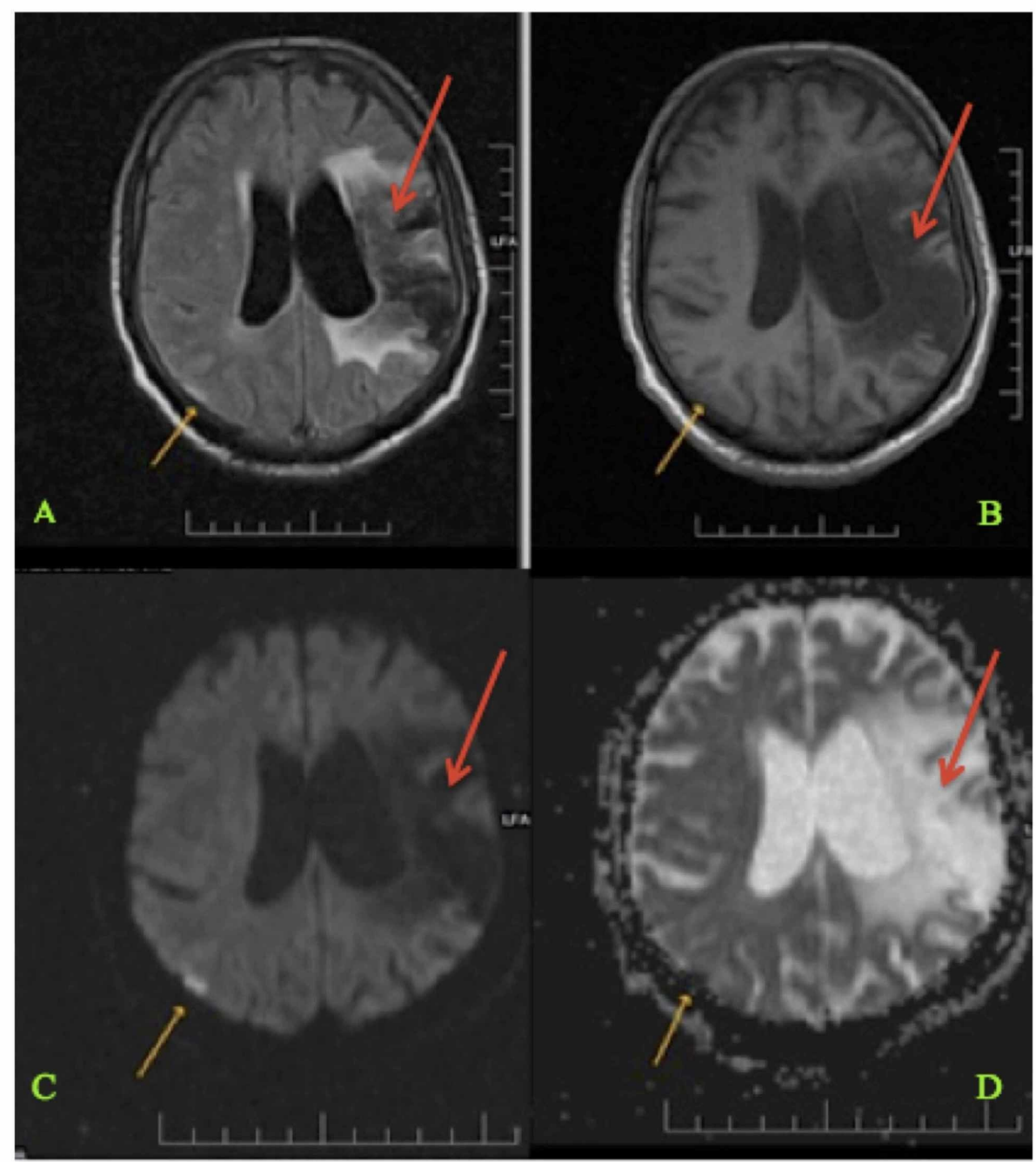

\section{FIGURE 1: Magnetic Resonance Imaging (MRI) of the Brain Showing}

Current and Previous Infarction Sites (Panels A-D)

Magnetic resonance imaging (MRI) of the brain showing an acute right-sided parietal lobe infarct (shown with yellow arrows) and an old left-sided middle cerebral artery territory infarct (shown with red arrows) in a 63year-old patient [9].

The TOAST classification utilizes five subcategories: large artery disease, cardioembolism, small vessel occlusion, other determined etiology, and undetermined etiology. Evidence from the TOAST classification points to a single cause while neglecting other associated diseases. The ASCOD classification includes atherothrombosis, small vessel disease, cardiac pathology, other causes, and dissection. For each patient, ASCOD assigns the probability of each category being responsible for stroke occurrence. We determined the frequency of each stroke etiology/mechanism according to both classification systems and the most predominant mechanism in each classification system.

\section{Results}

We evaluated a total of 209 patients (mean age: 61 years), of which $64 \%$ were men and $36 \%$ were women. The baseline characteristics of the study population were identified and evaluated (see Table 1). The prevalence of risk factors in our study was as follows: hypertension (60\%), diabetes (32\%), ischemic heart disease (11\%), heart valve pathology (4\%), and dyslipidemia (3\%). The determined prevalence of personal habits documented was found to be smoking (14\%), tobacco (6\%), and alcohol (5\%). Despite the recognized association between smoking as a risk factor and stroke incidence, there is a high likelihood that patients 


\section{Cureus}

underreported their smoking habit as it is considered socially unacceptable in that area of the world [10]. Using the ASCOD classification, we found that A was present in $42 \%$ of patients $(\mathrm{A} 1=21 \%, \mathrm{~A} 2=8 \%, \mathrm{~A} 3=$ $13 \%)$, S was present in $44 \%$ of patients ( $\mathrm{S} 1=9 \%, \mathrm{~S} 2=1 \%, \mathrm{~S} 3=34 \%), \mathrm{C}$ was present in $17 \%$ of patients $(\mathrm{C} 1=$ $6 \%, \mathrm{C} 2=4 \%, \mathrm{C} 3=7 \%)$, $\mathrm{O}$ was present in $5 \%$ of patients $(\mathrm{O} 1=5 \%)$, and $\mathrm{D}$ was present in $<1 \%$ of patients (see Figure 2). The TOAST classification showed LAA (33\%), SVO (29\%), CE (13\%), other causes (6\%), and undetermined (18\%) (see Figure 3). In the ASCOD classification, there was an overlap of disease between grades 1 and 2 (3\%) and when extended to grade 3 the overlap was $26 \%$.

\begin{tabular}{|l|l|}
\hline Characteristics Identified & Study Popu \\
\hline Median age of patients & 61 \\
Number of women & $75(36 \%)$ \\
Risk factors & \\
Hypertension & $125(60 \%)$ \\
Diabetes & $66(32 \%)$ \\
Ischemic heart disease & $22(11 \%)$ \\
Dyslipidemia & $7(3 \%)$ \\
Coronary revascularization & $5(2 \%)$ \\
Heart valve pathology & $8(4 \%)$ \\
Smoking & $30(14 \%)$ \\
Tobacco & $13(6 \%)$ \\
Alcohol & $11(5 \%)$ \\
Diagnostic evaluation & \\
Brain imaging & $18(2 \%)$ \\
CT or MRA & $175(84 \%)$ \\
ECG & $127(61 \%)$ \\
Echocardiography & $209(100 \%)$ \\
Secondary prevention & $107(51 \%)$ \\
Anticoagulant treatment & $160(77 \%)$ \\
Antiplatelet treatment & $58 \%)$ \\
\hline Throtin treatment & \\
\hline
\end{tabular}

\section{TABLE 1: Baseline Characteristics of the Study Population}

The prevalence of risk factors in the study population (209 patients) is presented in the above table. Certain factors such as hypertension (60\%) and diabetes $(32 \%)$ were represented more.

No: number; CT: computed tomography; MRA: magnetic resonance angiography; ECG: electrocardiogram. 


\section{Cureus}

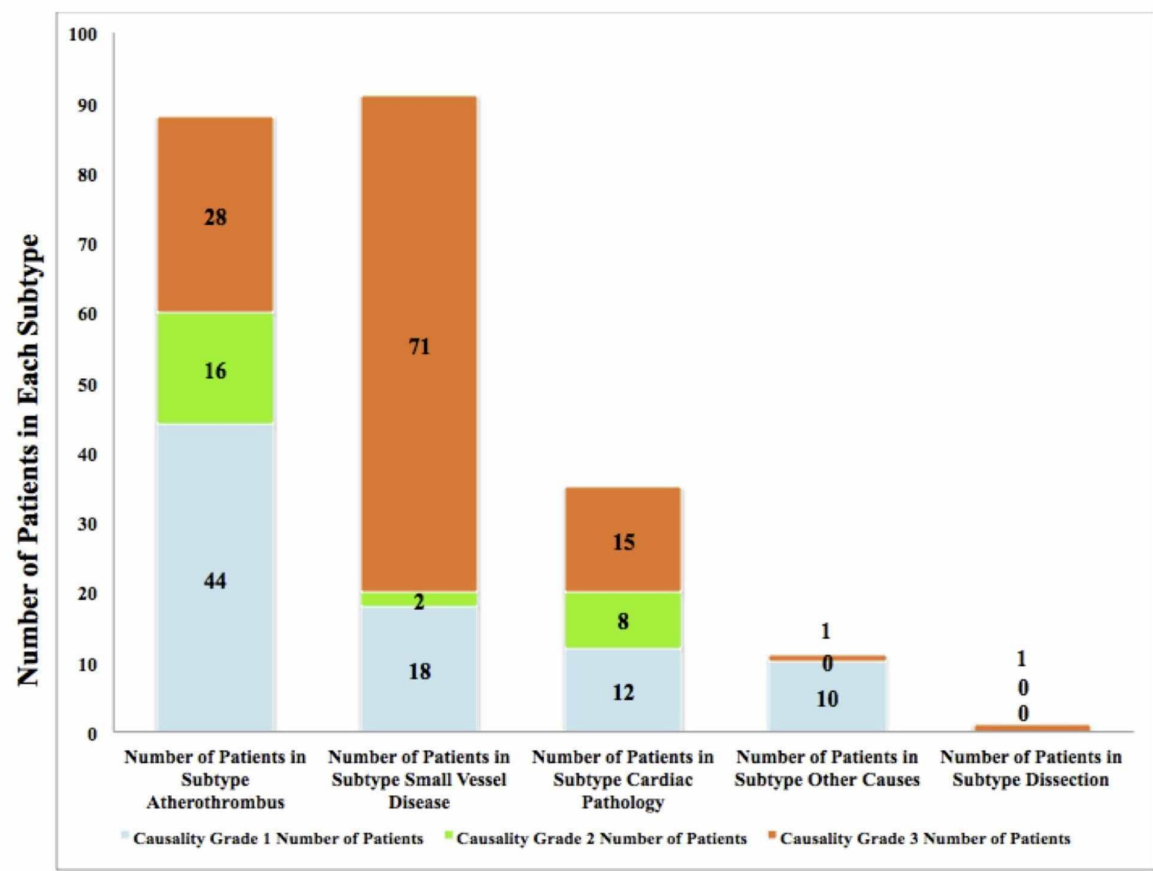

Subtype Classifications of ASCOD Classification

\section{FIGURE 2: ASCOD Classification of Stroke Patients in the Study}

A bar graph was created to represent patient distribution into different subtypes of the ASCOD classification (seen with bars). Each subtype was then further classified into different causality grades (blue, green, and orange). With the ASCOD classification, it was determined that $A$ was present in $42 \%$ of patients $(A 1=44$, $A 2=16, A 3=28), S$ was present in $44 \%$ of patients $(S 1=18, S 2=2, S 3=71), C$ was present in $17 \%$ of patients $(C 1=12, C 2=8, C 3=15)$, $O$ was present in $5 \%$ of patients $(O 1=10)$, and $D$ was present in $1 \%$ of patient. The patient population used comprised 209 people.

ASCOD: atherothrombosis (A), small vessel disease (S), cardiac pathology (C), other Causes (O), dissection (D); A1: atherothrombosis grade 1; A2: atherothrombosis grade 2; A3: atherothrombosis grade 3; S1: small vessel disease grade 1; S2: small vessel disease grade 2; S3: small vessel disease grade 3; C1: cardiac pathology grade 1; C2: cardiac pathology grade 2; C3: cardiac pathology grade 3; O1: other causes grade 1.

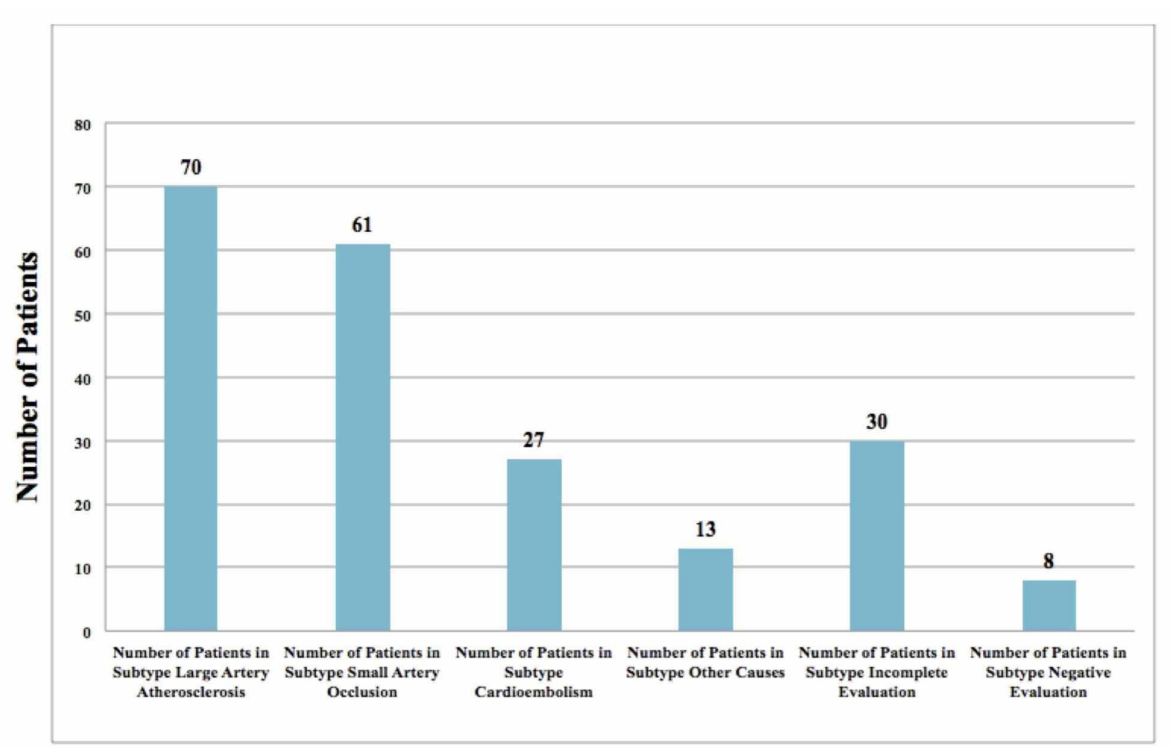

Subtypes of TOAST Classification

FIGURE 3: TOAST Classification of Stroke Patients in the Study 


\section{Cureus}

A bar graph was created to represent patient distribution according to the TOAST classification. The $x$-axis represents the subtypes of TOAST classification and the $y$-axis represents the number of patients in each subtype. The study population comprised 209 patients. The TOAST classification showed LAA (70), SVO (61), CE (27), other causes (13), and undetermined (30).

TOAST: Trial of Org 10172 in Acute Stroke Treatment; LAA: large artery atherosclerosis; SVO: small vessel occlusion; CE: cardioembolism.

Diagnostic evaluation was necessary in both classifications to further categorize each patient. In our study, we found the prevalence of conclusive brain imaging (84\%), CT angiography (CTA) or magnetic resonance angiogram (MRA) (61\%), ECG (100\%), and echocardiography (51\%). The prevalence of incomplete evaluations consisting of brain imaging (16\%), CTA or MRA (39\%), or echocardiography (49\%) was indicated by discharges against medical advice. These patients had financial restrictions, they refused to give consent for the procedure, or their power of attorney requested a transfer to another hospital.

\section{Discussion}

The TOAST classification was used to classify subtypes of ischemic stroke. TOAST helped neurologists to further determine the treatment, the prognosis, and the recurrence of stroke in these patients [7]. Similarly, the ASCOD classification is a phenotypic classification that broadly lists all the possible causes that could lead to stroke. Based on the degree of evidence, each disease can be certain, uncertain, unlikely, negative, or incompletely studied as a link to stroke [8]. Both classifications require an extensive workup, and incomplete investigations can lead to deficiencies in proper classification.

The ASCOD classification has yet to be utilized in the current scenario in India. Many studies online still research stroke subtypes by using the TOAST classification. The limitation of the TOAST classification is that it focuses on a single cause for stroke. By directing treatment to a single cause, inadequate treatment is being given to patients. Clinicians can potentially overlook the possibility of other diseases that if left undiagnosed, could lead to stroke recurrence. The main advantage of the ASCOD classification is that it gives a proper picture of the patient's present causative factor and other factors which can possibly lead to further recurrences. In our study population ( $n=209$ patients), we found an overlap of $3 \%$ of patients (ASCOD grades 1-2) and 55\% of patients (ASCOD grades 1-3). This showed substantial evidence that stroke mechanism/etiology is interconnected to multiple causes. In contrast, the TOAST classification denotes only a single cause for stroke but eliminates the possibility of other involved contributing factors. The ASCOD classification gives suitable secondary prevention measures based on the diseases linked to stroke. National application of this classification can lead to better primary and secondary prevention in these patients.

As of now, there are no available studies for the application of the ASCOD classification in an Indian setup. Few studies have utilized the TOAST classification for subtype determination (see Table 2). As physicians, we hope to incorporate more ASCOD classifications in our approach to ischemic stroke, possibly because in the past couple of years more of the world has adopted the ASCOD classification (see Table 3).

\section{Location in India}

Pramukhswami Medical College, Karamsad, Gujarat, India ( $n=209)$

Nizam's Institute of Medical Sciences, Hyderabad, Telangana, India $(\mathrm{n}=392)[11]$

All India Institute of Medical Sciences, Delhi, India $(n=440)$ [12]

\begin{tabular}{|c|c|c|c|c|c|c|}
\hline Authors & $\begin{array}{l}\text { Age } \\
\text { Group }\end{array}$ & LAA & SVO & CE & $\begin{array}{l}\text { Other } \\
\text { Causes }\end{array}$ & $\begin{array}{l}\text { Undetermined } \\
\text { Causes }\end{array}$ \\
\hline $\begin{array}{l}\text { Current } \\
\text { study }\end{array}$ & $\begin{array}{l}2-96 \\
\text { years }\end{array}$ & $33 \%$ & $29 \%$ & $13 \%$ & $6 \%$ & $18 \%$ \\
\hline $\begin{array}{l}\text { Kaul et al. } \\
2002\end{array}$ & $\begin{array}{l}2-97 \\
\text { years }\end{array}$ & $41 \%$ & $18 \%$ & $10 \%$ & $4 \%$ & $27 \%$ \\
\hline $\begin{array}{l}\text { Dash et al. } \\
2014\end{array}$ & $\begin{array}{l}18-45 \\
\text { years }\end{array}$ & $4.7 \%$ & $6.8 \%$ & $14 \%$ & $17.3 \%$ & $57 \%$ \\
\hline
\end{tabular}

\section{TABLE 2: TOAST Classification Studies Conducted in India}

n: number of patients; LAA: large artery atherosclerosis; SVO: small vessel disease; CE: cardioembolism; TOAST: Trial of Org 10172 in Acute Stroke Treatment. 


\section{Cureus}

\begin{tabular}{|c|c|c|}
\hline $\begin{array}{l}\text { Author } \\
\text { Name } \\
\text { and } \\
\text { Year of } \\
\text { the } \\
\text { Study }\end{array}$ & $\begin{array}{l}\text { Study } \\
\text { Population }\end{array}$ & Observation \\
\hline $\begin{array}{l}\text { Gökçal } \\
\text { et al. } \\
2017 \\
{[13]}\end{array}$ & 151 patients & $\begin{array}{l}\text { Using the TOAST classification, patient stroke etiology was classified into undetermined }(41.1 \%) \text {, CE } \\
(19.2 \%) \text {, LAA }(13.2 \%) \text {, SVO }(11.3 \%) \text {, and other causes }(15.2 \%) \text {. Compared to the TOAST classification, ASCO } \\
\text { classification assigned fewer patients to undetermined etiology subtype }(26.5 \%, p<0.001) \text { and SVO category } \\
(21.9 \%, p<0.001) \text {. ASCO also assigned more patients to the LAA group }(16.6 \%) .\end{array}$ \\
\hline $\begin{array}{l}\text { Arsava } \\
\text { et al. } \\
2017 \\
{[14]}\end{array}$ & $\begin{array}{l}1,816 \\
\text { patients }\end{array}$ & $\begin{array}{l}\text { The classification systems were different in their ability to assign stroke etiologies to known subtypes; the } \\
\text { size of the undetermined category was } 53 \% \text { per the TOAST classification and } 42 \% \text { per the ASCO } \\
\text { classification ( } p<0.001 \text { for all binary comparisons). }\end{array}$ \\
\hline $\begin{array}{l}\text { Markaki } \\
\text { et al. } \\
2013 \\
{[15]}\end{array}$ & $\begin{array}{l}101 \\
\text { patients, } 84 \\
\text { with } \\
\text { ischemic } \\
\text { stroke and } \\
17 \text { with a } \\
\text { TIA }\end{array}$ & $\begin{array}{l}\text { There was a moderately high agreement between the TOAST and ASCO classifications in all subtypes. } \\
\text { Along with the classification, the one- and four-year mortality rates were observed during a mean } \\
\text { observation period of } 28 \text { months, during which } 26 \text { patients died. The one- and four-year mortality rates, } \\
\text { respectively, were } 0 \% \text { and } 4 \% \text { in LAA, } 23 \% \text { and } 36 \% \text { in CE, } 0 \% \text { in SVO, } 63 \% \text { and } 100 \% \text { in unknown } \\
\text { etiology, and } 12 \% \text { and } 29 \% \text { in the cryptogenic subtype. For the ASCO classification, the one-year and four- } \\
\text { year mortality rates, respectively, were } 0 \% \text { and } 6 \% \text { in LAA, } 25 \% \text { and } 36 \% \text { in CE, } 0 \% \text { in SVO, } 0 \% \text { and } 14 \% \text { in } \\
\text { LAA + CE, } 16 \% \text { and } 36 \% \text { in SVO + CE, and } 56 \% \text { and } 100 \% \text { in the undetermined etiology despite complete } \\
\text { workup. }\end{array}$ \\
\hline $\begin{array}{l}\text { Shang } \\
\text { et al. } \\
2012 \\
{[16]}\end{array}$ & $\begin{array}{l}425 \text { patients } \\
\text { with first } \\
\text { time } \\
\text { ischemic } \\
\text { stroke }\end{array}$ & $\begin{array}{l}\text { There was a moderately high agreement between the TOAST and ASCO classification in all subtypes except } \\
\text { the "undetermined" etiology subtype }(16.2 \% \text { vs. } 15.5 \%, p=0.795) \text {. }\end{array}$ \\
\hline $\begin{array}{l}\text { Wolf et } \\
\text { al. } 2012 \\
{[17]}\end{array}$ & 103 patients & $\begin{array}{l}\text { identified in } 60.19 \% \text { A, } 75.73 \% \mathrm{~S}, 49.51 \% \mathrm{C} \text {, and } 3.88 \% \text { O. Around } 68.93 \% \text { of the patients were classified in } \\
\text { more than one category, and only } 3.88 \% \text { remained completely undetermined. With the TOAST classification, } \\
\text { the distribution was } 9.71 \% \text { in A, } 23.30 \% \text { in } \mathrm{S}, 34.95 \% \text { in C, } 1.94 \% \text { in O, and } 30.10 \% \text { in the undetermined } \\
\text { subtype. }\end{array}$ \\
\hline
\end{tabular}

\section{TABLE 3: TOAST and ASCOD/ASCO Stroke Etiology Classification Studies Conducted Internationally}

TOAST: Trial of Org 10172 in Acute Stroke Treatment; CE: cardioembolism; LAA: large artery atherosclerosis; SVO: small vessel occlusion; ASCOD: atherothrombosis (A), small vessel disease (S), cardiac pathology (C), other causes (O), and dissection (D).

The Hyderabad study showed a similar median age of patients at 54 years compared to a median age of 61 years in our study [11]. The predominant subtype of ischemic stroke was LAA (41-33\%). Undetermined etiology was the second most common in that study [11]. This was mainly attributed to the lack of the new algorithm proposed by the Stop-Stroke Study TOAST in 2005 [18]. The new modifications to the TOAST classification expanded the definitions of SVO and LAA that then decreased the undetermined subtype to $4 \%$ [18]. Our study still had a large proportion of undetermined cases (18\%), which were due to incomplete evaluation (14\%) and negative evaluation (4\%). The reasons for incomplete evaluation included financial restraints of the patients, negative consent by the relatives, request for transfer, or death of the patient. In India, financial restraints proved to be the greatest barrier to proper evaluation of a stroke patient. For additional information on the TOAST and ASCOD classifications, see the appendix for Tables 4-11.

\section{Conclusions}

Stroke is a complex disease with numerous contributing factors. Without a standardized protocol, it becomes difficult to collect data on patients, follow up, and provide treatment. The ASCOD classification is a better fit for patients of the Indian population and helps in deciding secondary prevention appropriately. However, we need to continue evaluating its applicability by motivating more physicians to generate larger prospective studies utilizing the ASCOD classification. Only with further studies can physicians come closer to a more standardized approach to ischemic stroke classification. 


\section{Cureus}

\section{Appendices}

Trial of Org 10172 in Acute Stroke Treatment (TOAST) Classification [7]

Classification of Subtypes of Ischemic Stroke

\begin{tabular}{|c|c|c|c|c|c|c|}
\hline $\begin{array}{l}\text { Large Artery } \\
\text { Atherosclerosis }\end{array}$ & $\begin{array}{l}\text { Small } \\
\text { Vessel } \\
\text { Occlusion }\end{array}$ & Cardioembolism & $\begin{array}{l}\text { Stroke of Other } \\
\text { Determined } \\
\text { Etiology }\end{array}$ & $\begin{array}{l}\text { Stroke of } \\
\text { Undetermined } \\
\text { Etiology }\end{array}$ & $\begin{array}{l}\text { Stroke of Undetermined } \\
\text { Etiology with a Negative } \\
\text { Evaluation }\end{array}$ & $\begin{array}{l}\text { Stroke of Undetermined } \\
\text { Etiology with an Incomplete } \\
\text { Evaluation }\end{array}$ \\
\hline
\end{tabular}

\section{TABLE 4: TOAST Classification [7]}

A table was created representing the different subtypes of the TOAST Classification [7].

TOAST: Trial of Org 10172 in Acute Stroke Treatment.

ASCOD Classification [8]

Classification of Subtypes of Ischemic Stroke

Atherothrombosis (A) Small Vessel Disease (S) $\quad$ Cardiac Pathology (C) $\quad$ Other Causes (O) Dissection (D)

\section{TABLE 5: ASCOD Classification [8]}

A table was created representing the different causality grades, as an underlying etiology of ischemic stroke as per a subcategory of the ASCOD classification [8].

ASCOD: atherothrombosis, small vessel disease, cardiac pathology, other causes, and dissection classification. 


\section{Cureus}

The Causality Grades [8]

A1: potentially causal. A stroke that is atherothrombotic is defined as one of the following:

A2: the causal link is uncertain. Defined as potentially one of the following:
ASCOD Atherothrombosis (A) Phenotypes According to Classification [8]

\section{An ipsilateral atherosclerotic \\ An ipsilateral atherosclerotic stenosis} stenosis of $50-99 \%$ in an intracranial or extracranial artery supplying the ischemic field.

An ipsilateral atherosclerotic stenosis of $30-50 \%$ in an intracranial or extracranial artery supplying the ischemic field.

A3: the causal link is unlikely, but the disease is present. One or more of the following may be seen:

A plaque (stenosis $<30 \%$ ) in an intracranial or extracranial artery, which is ipsilateral to the infarct area.

\section{A0: atherosclerosis} is not detected. In order to rule out atherosclerosis, the following should be looked for:

A negative finding for an extracranial arterial stenosis on US-duplex, CTA, MRA, XRA, or autopsy.

US-duplex, US-TCD or CTA, or MRA, or XRA or autopsy has not been performed. endoluminal thrombus
A9: an incomplete workup done on the patient. There will be a lack of tests performed such as the following:
An aortic plaque $\geq 4 \mathrm{~mm}$ without a mobile lesion. $<50 \%$ in an intracranial or extracranial artery with an supplying the ischemic A mobile
thrombus in the
aortic arch. An ipsilateral arterial occlusion in an intracranial or extracranial artery with evidence of underlying atherosclerotic plaque supplying the ischemic field.

\section{TABLE 6: Atherothrombus (A) ASCOD Classification with Causality Grades [8]}

A table was created representing the different causality grades, as an underlying etiology of ischemic stroke as per a subcategory of the ASCOD classification [8].

A: atherothrombosis; MR-DWI: magnetic resonance diffusion-weighted imaging; US-Duplex: ultrasound duplex; CTA: computed tomography angiography; MRA: magnetic resonance angiography; XRA: X-ray angiography; US-TCD: ultrasound transcranial Doppler; TEE: transesophageal echocardiography. 


\section{Cureus}

The Causality Grades [8]

S1: potentially causal. A stroke that will have a combination of a lacunar artery infarction on an MRI-DWI in an area corresponding to the symptoms and at least one out of the three following criteria:

S2: the causal link is uncertain. It is defined as potentially one of the following:

S3: the causal link is unlikely, but the disease is present.

S0: small vessel disease is not detected. In order to rule out small vessel disease, look for the following:

S9: an incomplete workup done on the patient. There will be a lack of tests performed such as:

ASCOD Small Vessel Disease (S) Phenotypes According to Classification [8]

One or several small deep older infarct(s) of lacunar type in other territories.

Only one recent lacunar infarction and no other abnormality is seen on MRI or CT.

There are severe white matter lesions

representative of small vessel ischemia visible on an MRI or CT scan.

Patient has anegative MRI (T2, FLAIR, GRE, DWI).

MRI
The patient has severe white matter lesions, small vessel ischemia, microbleeds, or severe dilatation of perivascular spaces.

The patient has a clinical syndrome suggestive of a deep branch artery stroke, without an ischemic lesion in the appropriate area.

There are microbleeds There is a severe There are one or seen on a T2weighted MRI. dilatation of the several old perivascular space small, and deep visible on T2infarcts of the weighted MRI. lacunar type.

There is no appropriate clinical syndrome suggestive of a deep branch artery stroke.

CT scan

\section{TABLE 7: Small Vessel Disease (S) ASCOD Classification with Causality Grades[8]}

A table was created representing the different causality grades, as an underlying etiology of ischemic stroke as per a subcategory of the ASCOD classification [8].

ASCOD: atherothrombosis, small vessel disease, cardiac pathology, other causes, and dissection classification; MRI-DWI: magnetic resonance diffusion-weighted imaging; MRI: magnetic resonance imaging; CT: computed tomography; FLAIR: fluid-attenuated inversion recovery; GRE: gradient echo imaging; DWI: diffusion-weighted imaging. 


\section{Cureus}

The Causality Grades [8]

C1: potentially causal. A stroke that is cardiogenic is defined as an ischemic lesion and has signs of systemic embolism with detection of at least one of the following causes:

C2: the causal link is uncertain. Regardless of the cardiogenic stroke pattern, there may be:

C3: the causal link is unlikely, but the disease is present. It is defined as potentially one of the following:

C0: cardiac pathology is neither detected nor suspected. Workup needed to rule out cardiac pathology:

C9: an incomplete workup done on the patient. Minimum workup needed to rule out cardiogenic shock:
ASCOD Cardiac Pathology (C) Disease Phenotypes According to Classification [8]

Mitral stenosis, mechanical valve, myocardial infarction within four weeks, preceding the cerebral infarction, mural thrombus in the left cavities, aneurysm of the left ventricle, a history or presence of documented atrial fibrillation (either paroxysmal, persistent or permanent) or atrial flutter with or without left atrial thrombus or spontaneous echo, atrial disease (tachycardia-bradycardia syndrome), dilated or hypertrophic cardiomyopathies, left ventricle ejection fraction $<35 \%$, endocarditis, intracardiac mass, PFO and thrombus in situ, PFO and concomitant pulmonary embolism or proximal DVT preceding the index cerebral infarction, aforementioned cardiac pathologies (C1) with single or without obvious cerebral ischemic lesion

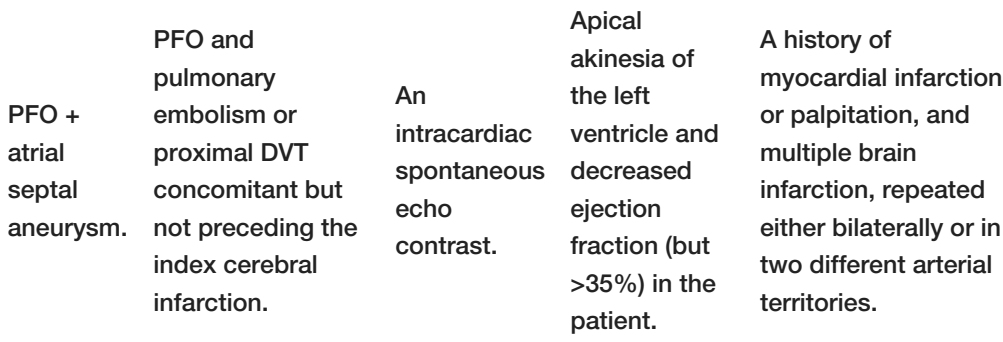

No direct cardiac source identified but multiple brain infarctions present and/or evidence of systemic emboli.

PFO, ASA, strands, mitral annulus calcification, calcification aortic valve, non-apical akinesia of the left ventricle, transient atrial fibrillation less than 1 minute in duration, atrial hyperexcitability.

The minimum workup needed is a negative ECG and an examination by a cardiologist.
The maximum workup needed is a negative ECG/telemetry/24hour Holter ECG/long-term ECG recording, a negative TEE, a negative TTE for PFO and assessment of left ventricle, a negative cardiac CT/MRI, and a negative abdominal CT/MRI.

\section{TABLE 8: Cardiac Pathology (C) of the ASCOD Classification with Causality Grades[8]}

A table was created representing the different causality grades, as an underlying etiology of ischemic stroke as per a subcategory of the ASCOD classification [8].

ASCOD: atherothrombosis, small vessel disease, cardiac pathology, other causes, and dissection classification; PFO: patent foramen ovale; DVT: deep venous thrombosis; ASA: atrial septal aneurysm; ECG: electrocardiogram; TEE: transesophageal echocardiography; TTE: transthoracic echocardiography; CT: computed tomography; MRI: magnetic resonance imaging. 


\section{Cureus}

The Causality Grades [8]

01: potentially causal. A stroke that is a result of other causes is defined as one of the following:

O2: the causal link is uncertain.

Regardless of the stroke pattern, there may be:

O3: the causal link is unlikely, but the disease is present. It is defined as potentially one of the following:

OO: it is neither detected nor suspected. In order to rule out other causes, there needs to be negative:

O9: an incomplete workup done on the patient.
ASCOD Other Causes (O) Phenotypes According to Classification [8]

\section{Dolichoectasia, A ruptured}

or elongated, distended, intracranial and tortuous cerebral aneurysm with or

arteries that may without vasospasm

present with of the artery

compressive or supplying the

ischemic symptoms. infarcted area.

A saccular aneurysm with suspicion of embolism.

A coincidental migraine attack with lasting neurological deficit.
Polycythemia vera or thrombocythemia, systemic lupus, antibody syndrome, Fabry disease, coexisting meningitis, sickle cell disease, severe hyperhomocysteinemia, Horton disease, other cerebral inflammatory or infectious angiitis, Moyamoya disease, etc. disseminated intravascular coagulation, antiphospholipid

Arteriovenous malformation, thrombocytosis, antiphospholipid antibody $<100 \mathrm{GPL}$ units, homocysteinemia $<40$ $\mu \mathrm{mol} / \mathrm{L}$, malignoma with an associated hypercoagulation, DVT or PE, and/or recent chemotherapy.

Cerebrospinal fluid, complete hemostasis, cerebral arterial imaging, family history of inherited disease, ESR, CRP, platelet count, leukocytes, and eosinophilic counts, hematocrit, and specific tests according to the suspected disease such as a genetic test or retinal angiography for Susac syndrome.

It is not possible to completely exclude other causes based on available diagnostic tests and stroke-specific history.

\section{TABLE 9: Other Causes (O) ASCOD Classification with Causality Grades [8]}

A table was created representing the different causality grades as an underlying etiology of ischemic stroke as per a subcategory of the ASCOD classification [8].

ASCOD: atherothrombosis, small vessel disease, cardiac pathology, other causes, and dissection classification; GPL: IgG phospholipid units; DVT: deep venous thrombosis; PE: pulmonary embolism; ESR: erythrocyte sedimentation rate; CRP: C-Reactive protein. 


\section{Cureus}

The Causality Grades [8]

\section{D1: potentially}

causal. A stroke

caused by dissection

can be a result of one

of the following:

D2: the causal link is

uncertain. It is defined

as potentially one of

the following:

D3: the causal link is unlikely, but the disease is present. Defined as potentially one of the following;

D0: dissection is neither detected nor suspected. In order to rule it out, the following should be done:

D9: an incomplete workup done on the patient. Minimum workup needed to rule out dissection is:

ASCOD Dissection (D) Disease Phenotypes According to Classification[8]

An arterial dissection demonstrated by a hypersignal on FAT-saturated MRI, autopsy, TOF-MRA, CT scans, increased arterial diameter.

An arterial dissection diagnosed based on a suggestive clinical history like a past history of dissection or Horner's syndrome.

There is kinking or dolichoectasia (elongated, distended, and tortuous cerebral arteries that may present with compressive or ischemic symptoms) without complicated aneurysm or plicature.
A demonstration of an arterial dissection by an indirect demonstration or by less sensitive or less specific diagnostic test (XRA, echocardiography, CTA, MRA, US) like an arterial stenosis seen without demonstration of the arterial wall hematoma

If there is imaging evidence of fibromuscular dysplasia of a cerebral artery of an involved cerebral field present.

There are arteries not implicated in the current ischemia that have evidence of fibromuscular dysplasia.

There are negative extra- and A negative

A negative A There is a lack of fat-saturated normal clinical suspicion of MRI. XRA. dissection cardiac intracranial cerebral artery evaluations.

\section{TABLE 10: Dissection (D) ASCOD Classification with Causality Grades [8]}

A table was created representing the different causality grades as an underlying etiology of ischemic stroke as per a subcategory of the ASCOD classification [8].

ASCOD: atherothrombosis, small vessel disease, cardiac pathology, other causes, and dissection classification; MRI: magnetic resonance imaging; TOF-MRA: time-of-flight magnetic resonance angiography; CT: computed tomography; XRA: X-ray angiography; CTA: computed tomography angiography; MRA: magnetic resonance angiography; US: ultrasound. 


\section{Cureus}

\begin{tabular}{|c|c|c|c|c|}
\hline $\begin{array}{l}\text { Classification } \\
\text { Systems }\end{array}$ & $\begin{array}{l}\text { Type of } \\
\text { Classification }\end{array}$ & Evidence Grade & Advantages & Disadvantages \\
\hline $\begin{array}{l}\text { TOAST } \\
\text { Classification } \\
\text { [7] }\end{array}$ & Causative & Probable/possible & $\begin{array}{l}\text { Convenient; can be used in clinical } \\
\text { practice }\end{array}$ & $\begin{array}{l}\text { Usage depends on the clinical } \\
\text { expertise of the physician; } \\
\text { overestimates the } \\
\text { undetermined group; evidence } \\
\text { grades are neglected }\end{array}$ \\
\hline $\begin{array}{l}\text { ASCOD } \\
\text { Classification } \\
\text { [8] }\end{array}$ & Phenotypic & $\begin{array}{l}\text { Disease } \\
\text { absent/potentially } \\
\text { causal/causal } \\
\text { link/uncertain causal } \\
\text { link/unlikely because of } \\
\text { insufficient workup }\end{array}$ & $\begin{array}{l}\text { Comprehensive workup; minimal and } \\
\text { maximal workup defined; overview of } \\
\text { all pathologies causing stroke; } \\
\text { correlates well with clinical studies; } \\
\text { good validity }\end{array}$ & $\begin{array}{l}\text { A complicated classification; } \\
\text { difficult to use in clinical } \\
\text { practice }\end{array}$ \\
\hline
\end{tabular}

TABLE 11: Classification System, Types, Evidence Grade, Advantages, and Disadvantages [7-8]

TOAST: Trial of Org 10172 in Acute Stroke Treatment; ASCOD: atherothrombosis, small vessel disease, cardiac pathology, other causes, and dissection classification.

\section{Additional Information \\ Disclosures}

Human subjects: Consent was obtained by all participants in this study. Institutional Ethics Committee issued approval ECR/331/Inst/GJ/2013. Approval of your research proposal submitted for Exempt Review. Animal subjects: All authors have confirmed that this study did not involve animal subjects or tissue. Conflicts of interest: In compliance with the ICMJE uniform disclosure form, all authors declare the following: Payment/services info: All authors have declared that no financial support was received from any organization for the submitted work. Financial relationships: All authors have declared that they have no financial relationships at present or within the previous three years with any organizations that might have an interest in the submitted work. Other relationships: All authors have declared that there are no other relationships or activities that could appear to have influenced the submitted work.

\section{References}

1. Aho K, Harmsen P, Hatano S, Marquardsen J, Smirnov VE, Strasser T: Cerebrovascular disease in the community: results of a WHO collaborative study. Bull World Health Organ. 1980, 58:113-30.

2. Sacco RL, Kasner SE, Broderick JP, et al.: An updated definition of stroke for the 21st century: a statement for healthcare professionals from the American Heart Association/American Stroke Association. Stroke. 2013, 44:2064-89. 10.1161/STR.0b013e318296aeca

3. Das SK, Banerjee TK, Biswas A, et al.: A prospective community-based study of stroke in Kolkata, India . Stroke. 2007, 38:906-10. 10.1161/01.STR.0000258111.00319.58

4. Katan M, Luft A: Global burden of stroke. Semin Neurol. 2018, 38:208-11. 10.1055/s-0038-1649503

5. GBD 2016 Stroke Collaborators: Global, regional, and national burden of stroke, 1990-2016: a systematic analysis for the Global Burden of Disease Study 2016. Lancet Neurol. 2019, 18:439-58. 10.1016/S14744422(19)30034-1

6. World Stroke Organization global stroke fact sheet. (2019). Accessed: May 26, 2019: https://www.worldstroke.org/images/WSO_Global_Stroke_Fact Sheet final.pdf.

7. Adams HP Jr, Bendixen BH, Kappelle LJ, Biller J, Love BB, Gordon DL, Marsh EE 3rd: Classification of subtype of acute ischemic stroke. Definitions for use in a multicenter clinical trial. TOAST. Trial of Org 10172 in Acute Stroke Treatment. Stroke. 1993, 24:35-41. 10.1161/01.STR.24.1.35

8. Amarenco P, Bogousslavsky J, Caplan LR, Donnan GA, Wolf ME, Hennerici MG: The ASCOD phenotyping of ischemic stroke (updated ASCO phenotyping). Cerebrovasc Dis. 2013, 36:1-5. 10.1159/000352050

9. Patel A R, Patel A R, Desai S: Acute hemiballismus as the presenting feature of parietal lobe infarction . Cureus. 2019, 11:4675. 10.7759/cureus.4675

10. Boehme AK, Esenwa C, Elkind MS: Stroke risk factors, genetics, and prevention. Circ Res. 2017, 120:472-95. 10.1161/CIRCRESAHA.116.308398

11. Kaul S, Sunitha P, Suvarna A, Meena AK, Uma M, Reddy JM: Subtypes of ischemic stroke in a metropolitan city of south India (one year data from hospital based stroke registry). Neurol India. 2002, 50:8-14.

12. Dash D, Bhashin A, Pandit AK, Tripathi M, Bhatia R, Prasad K, Padma MV: Risk factors and etiologies of ischemic strokes in young patients: a tertiary hospital study in north India. J Stroke. 2014, 16:173-77. 10.5853/jos.2014.16.3.173

13. Gökçal E, Niftaliyev E, Asil T: Etiological classification of ischemic stroke in young patients: a comparative study of TOAST, CCS, and ASCO. Acta Neurol Belg. 2017, 117:643-48. 10.1007/s13760-017-0813-8

14. Arsava EM, Helenius J, Avery R, et al.: Assessment of the predictive validity of etiologic stroke classification . JAMA Neurol. 2017, 74:419-26. 10.1001/jamaneurol.2016.5815 


\section{Cureus}

15. Markaki I, Franzén I, Talani C, Loizou L, Kostulas N: Long-term survival of ischemic cerebrovascular disease in the acute inflammatory stroke study, a hospital-based cohort described by TOAST and ASCO. Cerebrovasc Dis. 2013, 35:213-9. 10.1159/000346094

16. Shang Wy, Liu Jy: Stroke subtype classification: a comparative study of ASCO and modified TOAST . J Neurol Sci. 2012, 314:66-70. 10.1016/j.jns.2011.10.029

17. Wolf ME, Sauer T, Alonso A, Hennerici MG: Comparison of the new ASCO classification with the TOAST classification in a population with acute ischemic stroke. J Neurol. 2012, 259:1284-9. 10.1007/s00415-0116325-1

18. Ay H, Furie KL, Singhal A, Smith WS, Sorensen AG, Koroshetz WJ: An evidence-based causative classification system for acute ischemic stroke. Ann Neurol. 2005, 58:688-97. 10.1002/ana.20617 